\title{
Dutch senior medical students and disaster medicine: a national survey
}

Luc J. M. Mortelmans ${ }^{1,2^{*}}$, Stef J. M. Bouman³ ${ }^{3}$ Menno I. Gaakeer ${ }^{3}$, Greet Dieltiens ${ }^{1}$, Kurt Anseeuw ${ }^{1}$ and Marc B. Sabbe ${ }^{2,4}$

\begin{abstract}
Background: Medical students have been deployed in victim care of several disasters throughout history. They are corner stones in first-line care in recent pandemic planning. Furthermore, every physician and senior medical student is expected to assist in case of disaster situations, but are they educated to do so? Being one of Europe's densest populated countries with multiple nuclear installations, a large petrochemical industry and also at risk for terrorist attacks, The Netherlands bear some risks for incidents. We evaluated the knowledge on Disaster Medicine in the Dutch medical curriculum. Our hypothesis is that Dutch senior medical students are not prepared at all.

Methods: Senior Dutch medical students were invited through their faculty to complete an online survey on Disaster Medicine, training and knowledge. This reported knowledge was tested by a mixed set of 10 theoretical and practical questions.

Results: With a mean age of 25.5 years and $60 \%$ females, 999 participants completed the survey. Of the participants, $51 \%$ considered that Disaster Medicine should absolutely be taught in the regular medical curriculum and only $2 \%$ felt it as useless; $13 \%$ stated to have some knowledge on disaster medicine. Self-estimated capability to deal with various disaster situations varied from 1.47/10 in nuclear incidents to 3.92/10 in influenza pandemics. Self-estimated knowledge on these incidents is in the same line (1.71/10 for nuclear incidents and 4.27/10 in pandemics). Despite this limited knowledge and confidence, there is a high willingness to respond (ranging from 4.31/10 in Ebola outbreak over 5.21/10 in nuclear incidents to 7.54/10 in pandemics). The case/theoretical mix gave a mean score of 3.71/10 and raised some food for thought. Although a positive attitude, $48 \%$ will place contaminated walking wounded in a waiting room and $53 \%$ would use iodine tablets as first step in nuclear decontamination. Of the participants, $52 \%$ even believes that these tablets protect against external radiation, $41 \%$ thinks that these tablets limit radiation effects more than shielding and $57 \%$ believes that decontamination of chemical victims consists of a specific antidote spray in military cabins.
\end{abstract}

Conclusions: Despite a high willingness to respond, our students are not educated for disaster situations.

Keywords: Education; Disaster medicine; Medical students; Curriculum

\section{Background}

In the past, medical students have been involved in direct patient care in large-scale mass casualty incidents. From the Spanish flu pandemic in 1918 [1] over floodings [2], devastating earthquakes $[3,4]$ to the $9 / 11$ massacre [5], medical students have been deployed in victim care. The Belgian Royal Academy of Medicine even

\footnotetext{
*Correspondence: luc.mortelmans@zna.be

'Department of Emergency Medicine ZNA camp Stuivenberg, Lange Beeldekensstraat 267, B2060 Antwerp, Belgium

${ }^{2}$ Center for Research and Education in Emergency Care, Leuven, Belgium

Full list of author information is available at the end of the article
}

mentioned them as an important player in the national H5N1 pandemic plan in 2005 [6] although they were absolutely not prepared for it [7]. Despite the expectation of voluntary deployment, we know that training in Disaster Medicine has little to no place in regular medical curricula worldwide [8-16]. How can we rely on their help if they are not prepared? Our hypothesis is that, in the Netherlands, senior medical students are minimally prepared for direct patient care or other tasks during mass casualty incidents.

\section{倠 Springer}

(c) 2015 Mortelmans et al. Open Access This article is distributed under the terms of the Creative Commons Attribution 4.0 International License (http://creativecommons.org/licenses/by/4.0/), which permits unrestricted use, distribution, and reproduction in any medium, provided you give appropriate credit to the original author(s) and the source, provide a link to the Creative Commons license, and indicate if changes were made. 


\section{Methods}

To evaluate Disaster Medicine education amongst senior medical students, a descriptive cross-sectional study was performed in the academic year 2013-2014. The study was approved by the local ethical committee of ZNA, Antwerp.

Senior medical students (last 2 years of the 6 years of medical education) of the eight medical faculties that provide full medical training in The Netherlands were invited through their faculty and/or social media to complete an online survey (Survey Monkey, Palo Alto, California USA) on Disaster Medicine, training and knowledge. The survey (see Additional file 1: Figure S1) consisted of demographic data, prior education and selfestimated knowledge on and capability to deal with several disaster scenarios as well as their willingness to work in these circumstances. Scores were given on a scale from 0 to 10 . This reported knowledge was tested by a mixed set of 10 theoretical questions and practical cases, each correct answer valuing 1 point out of 10 . The survey was developed at the Center for Research and Education in Emergency Care (CREEC) at the University of Leuven based upon literature data and validated by several disaster specialists from the network of the CREEC and the Leuven University Disaster Management Course (joint venture with the Belgian Military and the Flemish Society of Emergency Nurses).

The data were statistically evaluated by the use of Stata SE 10.1 (StataCorp LP, College Station, Texas USA). We used where appropriate, the Pearson chi-square test, the two-sided $t$ test, the Wilcoxon-Mann-Whitney test, the Kruskal-Wallis test and the Pearson and Spearman correlation coefficients. A $p$ value smaller than 0.05 was considered to be significant.

Local student organisations were contacted to check to which extent Disaster Medicine courses (obligatory or voluntary) were incorporated in the local curriculum.

\section{Results}

Unfortunately, we could only approach students from six out of eight faculties as we were not allowed to contact students from both faculties in Amsterdam due to so-called survey overload. On a total population of 4408, 999 students participated, being a response rate of $22.66 \%$. Demographic data are grouped in Table 1. Selfestimated knowledge on and capability to deal with some specific disaster situations as well as willingness to assist in these situations during their apprenticeship are listed in Table 2. The mean score on the theoretical/case mix was 3.71/10 (0-10 SD 2.56), an overview of the questions and all results is given in Table 3. Some topics here are certainly food for thought; $48 \%$ directs potentially contaminated patients into the waiting room with all other patients at risk for contamination. There is a huge belief in the effects of iodine tablets: $52 \%$ is convinced that they protect against external radiation and up to $53 \%$ will use them as a first step in nuclear decontamination. Where $54 \%$ knows that that limiting time of exposure, increasing distance and shielding limits radiation damage the most, up to $41 \%$ will use iodine tablets for this purpose; $57 \%$ believes that decontamination of chemical victims consists of a specific antidote spray in military cabins.

Female and younger students scored better as well as students with prior knowledge or EMS experience. Those expressing the ambition to become a specialist score better than occupational or family physicians. Those who find it absolutely necessary to incorporate Disaster Medicine in the curriculum have a significant lower score than those feeling it useful. There is a very strong correlation between the test score and self-estimated knowledge, self-estimated capability and willingness to respond on the other hand.

There were no significant differences between the faculties, not in demographics nor in scores.

No universities offer any disaster medicine training in their curricula. Some students are informed during internship on EDs with a disaster prone staff but this on a

Table 1 Demographic data of our study population

\begin{tabular}{|c|c|c|}
\hline \multirow[t]{2}{*}{ Gender } & Male & $41 \%$ \\
\hline & Female & $59 \%$ \\
\hline Mean age & & $25.54(20-49)$ \\
\hline \multirow[t]{2}{*}{ Study year } & 5th & $50 \%$ \\
\hline & 6th (last) & $50 \%$ \\
\hline \multirow[t]{3}{*}{ Future orientation } & Family practice & $38 \%$ \\
\hline & Occupational/insurance & $2 \%$ \\
\hline & Specialisation & $60 \%$ \\
\hline \multirow{3}{*}{$\begin{array}{l}\text { Lives within } 20 \mathrm{~km} \\
\text { of nuclear installation }\end{array}$} & Yes & $2 \%$ \\
\hline & No & $69 \%$ \\
\hline & Don't know & $29 \%$ \\
\hline \multirow{3}{*}{$\begin{array}{l}\text { Lives within } 20 \mathrm{~km} \\
\text { of chemical installation }\end{array}$} & Yes & $16 \%$ \\
\hline & No & $28 \%$ \\
\hline & Don't know & $56 \%$ \\
\hline \multirow[t]{2}{*}{ Any EMS/DM experience } & Yes & $7 \%$ \\
\hline & No & $93 \%$ \\
\hline \multirow[t]{2}{*}{ Has some DM knowledge } & Yes & $13 \%$ \\
\hline & No & $87 \%$ \\
\hline \multirow{3}{*}{$\begin{array}{l}\text { DM needs to be trained } \\
\text { within curriculum }\end{array}$} & Absolutely & $51 \%$ \\
\hline & Useful & $48 \%$ \\
\hline & Useless & $1 \%$ \\
\hline
\end{tabular}


Table 2 Scores in mean (minimum-maximum) of the 0-10 visual analogical scale on self-estimated knowledge and capabilty and willingness to respond in the evaluated disaster situations

\begin{tabular}{llll}
\hline & $\begin{array}{l}\text { Self-estimated } \\
\text { knowledge }\end{array}$ & $\begin{array}{l}\text { Self-estimated } \\
\text { capability }\end{array}$ & $\begin{array}{l}\text { Willingness } \\
\text { to respond }\end{array}$ \\
\hline Nuclear incidents & $1.71 / 10(0-8)$ & $1.47 / 10(0-9)$ & $5.21 / 10(0-10)$ \\
Chemical incidents & $2.28 / 10(0-8)$ & $1.85 / 10(0-8)$ & $5.87 / 10(0-10)$ \\
Biological incidents & $2.28 / 10(0-8)$ & $2.04 / 10(0-8)$ & $6.61 / 10(0-10)$ \\
$\begin{array}{l}\text { Outbreak very infectious } \\
\text { disease (e.g. N5H1) }\end{array}$ & $4.27 / 10(0-10)$ & $3.92 / 10(0-9)$ & $7.54 / 10(0-10)$ \\
$\begin{array}{l}\text { Outbreak very } \\
\text { dangerous contagious } \\
\text { infection (e.g. Ebola) }\end{array}$ & $2.88 / 10(0-10)$ & $2.47 / 10(0-9)$ & $4.31 / 10(0-10)$ \\
\hline
\end{tabular}

voluntary unstructured base, not linked with the university curricula.

\section{Discussion}

In case of mass casualty incidents, all unaffected, available hands are expected to attend in controlling the situation. So every physician, whatever speciality he or she might have, should be able to assist [17]. When communities get isolated as in natural disasters, the family physicians could be the only source of medical relief until external help is organised [18]. In this option, the Association of American Medical Colleges did recommend that all medical schools should thoroughly educate their students about EMS to ensure coordinated responses to weapons of mass destruction or other public health threats [19]. However, recent evaluation proves that this exposure still is very limited with a call for a national curriculum $[20,21]$. Looking at the European situation, there is an established curriculum in Germany [22]. Italy is in the experimental phase testing a programme and educational methods in several medical schools [23] following a clear need expressed by the students [24]. Belgium has a limited introduction in three faculties [25].

Our findings demonstrate that medical students in The Netherlands perform not better compared with their Belgian colleagues. Despite a considerable willingness to respond in case of a disaster, education and training in disaster medicine are inadequate to meet these challenges. The students seem to be aware of this situation as half of the respondents find it absolutely necessary to incorporate it in their regular curriculum. They seem to be most at ease with infectious problems, probably due to the fact that this kind of pathology is discussed in regular lectures on internal medicine or infectiology. Despite media attention after the Fukushima incident, nuclear problems remain the big unknown. Perceived knowledge and capability is limited over different situations, and this was confirmed by the test with practical cases. Misconceptions on (de)contamination and radioprotective effects of iodine tablets create dangerous
Table 3 Overview of the answers on the theory/case mix questions

\begin{tabular}{lr}
\hline Q1/ Chain collision, possible cotaminated patients: & \\
Isolate in distal corner & $5 \%$ \\
In waiting room & $49 \%$ \\
In garage & $1 \%$ \\
Wait separately outside & $\mathbf{4 5} \%$ \\
No action, hide & $0 \%$ \\
Q2/ lodine tablets protect against: & \\
External radiation & $28 \%$ \\
Internal radiation & $\mathbf{1 5 \%}$ \\
Both external and internal & $24 \%$ \\
No radiation protection & $20 \%$ \\
Don't know & $13 \%$ \\
Q3/Tthe CGV means: &
\end{tabular}

Operational leader of overall disaster management $\quad 26 \%$

Controlling arriving ambulances $\quad 4 \%$

Field hospital supplies $\quad 2 \%$

Deciding which patients go where $\quad 14 \%$

Don't know $55 \%$

Q4/ Postman with necrotic lesions:

Frostbite

$10 \%$

New chemical product $\quad 22 \%$

Possible anthrax $\quad 47 \%$

Use of new kind of black ink $\quad 1 \%$

Don't know $20 \%$

Q5/ Chemical decontamination:

Oral antidote $5 \%$

Antidote body smear $\quad 3 \%$

Antidote spray special miltary cabin $\quad 57 \%$

Wash with water and soap $\quad 15 \%$

Don't know $20 \%$

Q6/ What limits radiation damage the most?

Protective clothing $3 \%$

Fast decontamination $\quad 1 \%$

Oral iodine tablets $\quad 41 \%$

Limit time of exposure, increase distance and shielding $\quad 54 \%$

Don't know

Q7/ 2 most important objects to take along in evacuation:

Smartphone

$57 \%$

Laptop

ID/health insurance cards

Syllabus/handbook

Sixpack of beer

Normally used medication

Photo of loved one

\section{.}

\section{a} $\%$

\section{.} $\%$ 
Table 3 Overview of the answers on the theory/case mix questions (Continued)

\begin{tabular}{lr}
\hline None of the above & $6 \%$ \\
Don't know & $0 \%$ \\
Q8/ Superficial cuts and first degree burns, go to & $47 \%$ \\
Nearest hospital & $5 \%$ \\
Closest hospital with burn unit & $6 \%$ \\
Home (recover and sleep) & $\mathbf{4 1} \%$ \\
Hospital ED further away & $1 \%$ \\
Don't know & \\
Q9/ First step in nuclear decontamination & $8 \%$ \\
Shower patient & $\mathbf{2 3} \%$ \\
Administer iodine tablets & $4 \%$ \\
Take off clothes and shoes & $12 \%$ \\
Put on lead apron & \\
Don't know & $40 \%$ \\
Q10/ Traffic accident with 2 trucks and 2 victims, what to do? & $2 \%$ \\
Stop, call 112 and help lying victim & \\
Stop, call 112 and help limping victim & $\mathbf{5 4} \%$ \\
Stop at safe distance and wait for clearance fire brigade & $4 \%$ \\
Drive by and call 112 at hospital & $0 \%$ \\
Do as if nothing happened & \\
\hline
\end{tabular}

The correct answers are given in bold. The "don't know" option was added to eliminate wild guess bias

situations for themselves, patients and other healthcare professionals. Only implementation of a national (or European) curriculum on disaster management, not ready available at time of the study, can solve the problem. Our study however raised the awareness of this problem in one faculty (Rotterdam) where a voluntary basic course is considered.

Comparison with a recent similar survey amongst Belgian senior medical students [25] revealed a lower mean test score, a lower willingness to respond and a lower estimated capability in chemical and infectious incidents in our study population.

Recruiting the students was a major limitation in this project. We could only contact the students by medical faculties with variable levels of cooperation and/or by social media groups. In an era of survey fatigue, this complex procedure will limit participation to really motivated persons so our results may potentially be too optimistic. Anonymous participation in this online survey limits scientific control on participants so eventual duplicate results cannot be excluded. Depending on self-reported information could bias the results as well; however, the strong correlation between estimated knowledge and capability and test score on the other hand limits this assumption. Exclusion of the Amsterdam students could also bias our results. We do hope this effect is limited as there were no differences in demographics and results between all other faculties.

\section{Conclusions}

In conclusion, we could state that Dutch senior medical students do believe in the usefulness of teaching Disaster Medicine in the regular curriculum. Although knowledge and estimated capability are limited, there is a relative high willingness to respond. Development and implementation of European guidelines could help to establish a basic training preparing them for a real incident.

\section{Additional file}

\section{Additional file 1: Figure S1. Survey used to evaluate disaster medicine} training/education. (PDF $130 \mathrm{~kb}$ )

\section{Competing interests}

The authors declare that they have no competing interests.

\section{Authors' contributions}

LM conceived the study, participated on survey design and literature study and drafted the manuscript. SB participated in recruiting and contacting the student organisations on social media. MG participated in study design and contacts with the faculties. GD and KA performed statistical analysis of the data. MS participated in study and survey design. All authors read and approved the final manuscript

\section{Acknowledgements}

The authors wish to thank the faculty administrators who contacted the students and those enthusiast students that promoted the survey with their colleagues. We also wish to thank Medica, the medical student group of the University of Leuven, Belgium, for kindly hosting the survey on their website and the Belgian Society of Emergency and Disaster Medicine for the use of their Survey Monkey account.

\section{Author details}

${ }^{1}$ Department of Emergency Medicine ZNA camp Stuivenberg, Lange Beeldekensstraat 267, B2060 Antwerp, Belgium. ${ }^{2}$ Center for Research and Education in Emergency Care, Leuven, Belgium. ${ }^{3}$ Department of Emergency Medicine Admiraal De Ruyterhospital, Goes, The Netherlands. ${ }^{4}$ Department of Emergency Medicine University Hospital Gasthuisberg, Leuven, Belgium.

Received: 27 May 2015 Accepted: 16 July 2015

Published online: 03 September 2015

\section{References}

1. Starr I. Influenza in 1918: recollections of the epidemic in Philadelphia. Ann Int Med. 2006:145(2):138-40.

2. Kshirsagar NA, Shinde RR, Mehta S. Floods in Mumbai: impact of public health service by hospital staff and medical students. J Postgrad Med. 2006;52:312-4

3. Reyes H. Student's response to disaster: a lesson for health care professional schools. Ann Intern Med. 2010;153(10):658-60.

4. Sabri AA, Qayyum MA. Why medical students should be trained in disaster management: our experience of the Kashmir Earthquake. PLoS Med. 2006;3(9):1452-3.

5. Katz CL, Gluck N, Maurizio A, DeLisi LE. The medical student experience with disasters and disaster response. CNS Spectr. 2002;7(8):604-10.

6. Belgian Royal Academy of Medicine. The coming influenza epidemic: a reason to prepare. Belg Tijdschr Gen. 2005;61(22):1577-82.

7. Mortelmans LIM, De Cauwer HG, Van Dyck E, Monballyu P, Van Giel R, Van Turnhout E. Are Belgian senior medical studenst ready to deliver basic medical care in case of a H5N1 pandemic? Prehosp Disaster Med. 2009;24(5):438-42. 
8. Scott LA, Carson DS, Greenwell IB. Disaster 101: a novel approach to disaster medicine training for health professionals. J Emerg Med. 2010;39(2):220-6.

9. Markenson D, DiMaggio C, Redlener I. Preparing health professions students for terrorism, disaster and public health emergencies: core competencies. Acad Med. 2005;80(6):517-26.

10. Accatino L, Figueroa RA, Montero J, Gonzalez M. The worrisome lack of disaster training in Latin American medical schools. Rev Panam Salud Publica. 2010;28(2):135-6.

11. Smith J, Levy MJ, Hsu EB, Levy JL. Disaster curricula in medical education: pilot survey. Prehosp Disaster Med. 2012;27(5):492-4.

12. Dembek $Z$, Iton A, Hansen H. A model curriculum for public health bioterrorism education. Pub Health Rep. 2005;120:11-8.

13. Altintas KH, Boztas G, Duyuler S, Duzlu M, Energin H, Ergun A. Differences in opinions on disaster myths between first year and sixth year medical students. Eur J Emerg Med. 2009;16(2):80-3.

14. Franc-Law JM, Ingrassia PL, Ragazzoni L, Della CF. The effectiveness of training with an emergency department simulator on medical student performance in a simulated disaster. CJEM. 2010;12(1):27-32.

15. Cummings GE, Della Corte F, Cummings GG. Disaster medicine education in Canadian medical schools before and after September 11, 2001. CJEM. 2005;7(6):399-405.

16. Ingrassia PL, Geddo A, Lombardi F, Calligaro S, Prato F, Tengattini M, et al. Teaching disaster medicine to medical students: "learning by doing" is a useful tool. Eur J Emerg Med. 2006;13(1):59-60.

17. Kaji $A H$, Coates W, Fung CC. A disaster medicine curriculum for medical students. Teach Learn Med. 2010;22(2):116-22.

18. Huntington MK, Gavagan TF. Disaster medicine training in family medicine: a review of the evidence. Fam Med. 2011:43(1):13-20.

19. Parrish AR, Oliver S, Jenkins D, Ruscio B, Green JB, Colenda C. A short medical shool course on responding to bioterrorism and other disasters. Acad Med. 2005;80(9):820-3.

20. Kaiser HE, Barnett DJ, Hsu EB, Kirsch TD, James JJ, Subbarao I. Perspectives of future physicians on disaster medicine and public health preparedness: challenges of building a capable and sustainable auxiliary medical workforce. Disaster Med Public Health Prep. 2009;3(4):210-6.

21. Jasper E, Berg K, Reid M, Gomella P, Weber D, Schaeffer A, et al. Disaster preparedness: what training do our interns receive during medical school? Am J Med Qual. 2013;28(5):407-13.

22. Pfenninger EG, Domres BD, Stahl W, Bauer A, Houser CM, Himmelseher S. Medical student disaster medicine education: the development of an educational resource. Int J Emerg Med. 2010;3:9-20.

23. Ingrassia PL, Ragazzoni L, Tengattini M, Carenzo L, Della CF. Nationwide program of education for undergraduates in the field of disaster medicine: development of a core curriculum centered on blended learning and simulation tools. Prehosp Disaster Med. 2014;29(5):508-15.

24. Ragazzoni L, Ingrassia PL, Gugliotta G, Tengattini M, Franc JM, Della CF. Italian medical students and disaster medicine: awareness and formative needs. Am J Disaster Med. 2013;8(2):127-36.

25. Mortelmans LJM, Dieltiens G, Anseeuw K, Sabbe MB. Belgian senior medical students and disaster medicine, a real disaster? Eur J Emerg Med. 2014;21(1):77-8

\section{Submit your manuscript to a SpringerOpen ${ }^{\circ}$ journal and benefit from:}

- Convenient online submission

- Rigorous peer review

- Immediate publication on acceptance

- Open access: articles freely available online

- High visibility within the field

- Retaining the copyright to your article

Submit your next manuscript at $>$ springeropen.com 